\title{
A COMPARISON OF NICHE ESTABLISHMENTS IN ENGLISH RESEARCH ARTICLE INTRODUCTIONS PUBLISHED IN INTERNATIONAL AND THAI JOURNALS
}

\section{Wirada Amnuai}

\begin{abstract}
The present study looked closely at the niche establishments in the introduction sections of English research articles written by Thai authors and published in local Thai journals and compared them to those found in introduction sections written by non-Thai authors published in international and high indexed journals. Each of the two corpora contains forty introductory sections. The analysis was based on the frameworks of Swales (2004) and Lim (2012). It was found that the use of niche establishments in the international corpus was higher than that in the Thai corpus. In the Thai corpus, "Stressing insufficient research" was the highest strategy, but "Revealing methodological limitations" was completely absent. It is expected that the results will provide practical guidance for novice writers to write their research introduction sections with informative and convincing niche establishments and, to some extent, the results should also benefit English writing classes, especially in Thailand.
\end{abstract}

\section{Keywords}

niche establishment, indicating a gap, introduction section, research article, genre analysis

\section{Introduction}

A research article (hereafter RA) is one of the academic genres that have been widely studied using genre-based approaches (e.g. Swales 1990, Yang \& Allison 2003, Kanoksilapatham 2005, Lim 2006, Ozturk 2007, Amirian et al. 2008, Pho 2008, Amnuai \& Wannaruk 2013). Since RAs are considered as an interesting and powerful genre used by scientific communities as a medium for circulating knowledge among scholars in different disciplines, most of the studies which analyze the rhetorical structure of RAs aim to show the connection between textual units and their communicative purposes with the intention of presenting a clear picture of how RAs are constructed rhetorically and linguistically, and also to provide a practical guide for novice writers of RAs on how to write effectively and productively. This will be of considerable value in helping writers who may have troubles with producing research articles for scholarly publications. As Joseph et al. (2014) stated, the results from genre-based approach research studies can assist learners with a greater awareness of the conventions of writing, so that they will be able to write their texts in a well-structured form with the appropriate terms for their linguistic choices. This will fully prepare students to enter the academic and professional discourse communities with confidence. 
As we know, writing RAs is viewed as a daunting task by novice writers, particularly non-native writers of English. As noted by Flowerdew (1999), written papers developed by non-native speakers show "the surface errors to be less problematic than the more abstract features of these papers" (ibid.: 127). They face such difficulties as textual organization, ways to embrace research issues and the audiences for their studies, as well as to contextualize their findings for a larger readership or make topic generalizations (Flowerdew 1999). This shows that both native and non-native writers of English need to be aware of the conventional rhetorical structures accepted in their fields or discourse communities (Kanoksilapatham 2005) because "scholarly texts vary in their level of interactivity both within and across academic communities" (Duszak 1997: 18).

In English for Special Purposes (ESP), genre analysis is focused on revealing the organization of communicative functions or moves. Swales (1990) defined a move as a structural segment that has a specific communication purpose using key linguistic features such as tense, voice, and grammar. Analyzing the RA sections of research articles using a move-based approach has been the focus of several research studies such as studies exploring abstracts (e.g. Hyland 2000, Pho 2008, Ahmed 2015), introductions (e.g. Swales 1990, Chang \& Schleppegrell 2011, Lim 2012, Josep et al. 2014), methods (e.g. Peacock 2011, Zhang \& Wannaruk 2016, Cotos et al. 2017), results (e.g. Brett 1994, Thompson 1993, Williams 1999), discussions (e.g. Yang \& Allison 2003, Amirian et al. 2008, Liu \& Buckingham 2018), and conclusions (e.g. Amnuai \& Wannaruk 2013, Zamani \& Ebadi 2016, Ali et al. 2019). These analysts believed that the results of a move-based analysis would yield practical knowledge of how rhetorical moves are realized linguistically and give a clearer understanding of the characteristics of a genre (i.e. a research article) shared by discourse communities. An awareness of these moves and their linguistic realizations will eventually facilitate the entry of novice writers into professional discourse communities (Joseph et al. 2014).

The research article introduction (hereafter RAI) is one of the most interesting aspects of the genre. To write introduction sections, writers need to write in as convincing and impressive a manner as possible so as to attract readers' attention. Generally, the function of an introduction section is to provide the general topic of the issue being studied and demonstrate its relationship to the current literature. Then, pointing out the research gap in previous studies is always stated and further information is given about the subject matter or the issue to be studied, which are all included in the introduction. Writers need to provide informative and appropriate knowledge to the reader and present it in the conventional style used by the members of their academic discourse community (Swales 1990, 
2004, Lim 2012). More importantly, in the introduction section, relevant studies are also expected to be referenced and cited. If all these rhetorical and linguistic devices flow smoothly, the readers will have a clear understanding of the issue or topic they are reading about, and they will be able to interpret it based on their own perspectives in the light of the present literature (Armağan 2013). Thus, all these characteristics show that writing an introduction to a research article can be a complicated but important task, particularly for novice writers.

Writing RAIs in English is demanding for unskilled writers, especially non-native writers of English (e.g. Flowerdew 1999, Swales 1990, Swales \& Feak 2004). As Swales (1990) noted, nearly all academic writers encounter difficulties in starting to write the introduction to a research article. This is because writers need to decide how to present their paper informatively in four aspects, including the appropriate amount and type of background knowledge, the authoritative versus the sincere stance, the winsomeness of the appeal to readership, and the directness of the approach. He also found that to convey the same meaning of a single text unit, different speakers of a language will present it in different language forms. For non-native speakers their first language is embedded and interferes with the target language. Besides, disciplinary and cross-linguistic variations also cause difficulties (e.g. Brett 1994, Valero-Garces 1996, Samraj 2002, Swales \& Feak 2004, Ozturk 2007).

Establishing niches is another issue that needs to be considered when writing RAIs. In order to convince readers of the importance of their research, establishing a research niche is crucial because it is in this way that writers are trying to position their research study for the discourse community (Swales 1990, 2004). Based on the seminal work by Swales (1990, 2004), establishing research niches is one of the three moves proposed in his CARS model (See Figure 1). It is Move 2, called "Establishing a niche" which is aimed to justify the research being reported (Samraj 2005). The aim of Move 2 is to connect Move 1 (Establishing a territory) to Move 3 (Presenting the present work), that is, it links what has already been presented in the literature to what the present research is about and Move 2 can be considered as a mini-critique (Shehzad 2008). It is an essential rhetorical strategy in presenting RAs to the field by arguing for the importance of one own's study (Moghaddasi \& Graves 2017). Niche establishment involves crediting and evaluating previous studies in creative ways, but not always in negative terms, and emphasizing the necessity, newness and importance of the current inquiry (Chen \& Li 2019). In other words, this move is viewed as a bridge connecting previous research studies with a new study being introduced in a research paper (Lim 2012). RAs with effective niche establishment reflect research quality which leads to their being accepted by international and well-known journals. 
Numerous research studies have analyzed RAIs using Swales' models (1990, 2004) which revealed that Move 2 (establishing a niche) is frequently found in RAIs in different disciplines (e.g. Swales \& Feak 2004, Samraj 2005, Loi 2010, Ozturk 2007, Del Saz-Rubio 2011, Lim 2012, Bruce 2014, Chen \& Li 2019). Furthermore, some studies have looked closely at the linguistic realizations employed in niche establishment (e.g. Shehzad 2008, Lim 2012, Moghaddasi $\&$ Graves 2017). These studies focused on analyses of different research areas. Chen and Li (2019) analyzed niche establishment in theses. Moghaddasi and Graves (2017) investigated discrete mathematics RAIs, and Lim (2012) analyzed niche establishment in management introductions. To my knowledge, there are no research studies which have analyzed niche establishments in RAIs written in English by Thai authors published in local Thai journals and compared to other international and well-known journals. Therefore, to fill this gap, the present study analyzed niche establishments in RAIs in two different published contexts with the aims of 1) investigating the niche establishments of RAIs in the two corpora, and 2) exploring how those niches were realized linguistically. It is expected that the rhetorical and linguistic results of the present study may provide insight into the ways writers establish niches. In addition, it might be useful for unskilled writers, especially Thai writers, to know how to create niches accurately and convincingly for their research papers.

Move 1: Establishing a territory (citations required) via topic generalizations of increasing specificity

Move 2: Establishing a niche (citations possible) via:

Step 1A: Indicating a gap, or

Step 1B: Adding to what is known

Step 2: Presenting positive justification (optional)

Move 3: Presenting the present work via:

Step 1: Announcing present research descriptively and/ or purposively (obligatory)

Step 2: Presenting research questions or hypotheses* (optional)

Step 3: Definitional clarifications* (optional)

Step 4: Summarizing methods* (optional)

Step 5: Announcing principal outcomes (optional) **

Step 6: Stating the value of the present research (optional) **

Step 7: Outlining the structure of the paper (optional) **

* Steps 2-4 are less fixed in their order of occurrence than the others

** Steps 5-7 are probable in some fields, but unlikely in others

Figure 1: Swales' CARS model (2004) 


\section{Method}

\subsection{The construction of the corpora}

There were two corpora in the present study (international corpus and Thai corpus). Each of them consisted of 40 RAIs in the field of applied linguistics. This field was the focus because it was of particular interest for pedagogical reasons (Yang \& Allison 2004), as well as also being an under-explored area of niche establishment. The international corpus contained 40 RAIs taken from four indexed journals: namely English for Specific Purposes, Journal of English for Academic Purposes, Journal of Phonetics, and System. On the other hand, 40 RAIs written by Thai authors were selected from four scholarly journals published by reputable universities in Thailand: namely, PASAA, Suranaree Journal of Social Sciences, The New English Teacher, and LEARN Journal: Language Education and Acquisition Research Network. The criteria for the selection of the journals in the international corpus were based on popularity, online accessibility, and impact factors according to the Scimago journal ranks (SJR) (2018), which can be accessed via https://www.scimagojr.com/journalrank.php. For the Thai corpus, besides having online accessibility and being peer-reviewed journals, these journals were in Tier 1 and Asian Citation Index (ACI) indices, accredited by the Thai-Journals Citation Index Center (TCI), and they can be tracked via https://tci-thailand.org/. PASAA journal was also indexed in the SCOPUS list. Using purposive sampling, ten RA introductions were taken from each journal. Only one RAI was taken from one volume or issue starting from the most recent volume or issue of each journal and stopping when ten introductions had been collected from each journal. Since this study focused on Thai writers, the authors or co-authors of the selected RAIs had to be Thai. RAIs of the international corpus were from journals published between 2017 and 2020, while those RAIs in the Thai corpus were drawn from journals published between 2008 and 2020.

\subsection{Niche establishment approaches}

Swales' (2004) move model was used as the framework for niche establishment. This model was used because it was originally developed from an analysis of RAIs and has been widely used as a framework in several research studies (Loi 2010, Sheldon 2011, Lim 2012, Moghaddasi \& Graves 2017). This framework was considered to be the most appropriate since it has been modified according to critical appraisals made by previous researchers (e.g. Antony 1999, Samraj 2002) and the modified version is believed to be the strongest version (Ozturk 2007, Loi \& Evans 2010). Swales' (2004) model has been applied in 
some studies (e.g. Moghaddasi \& Graves 2017, Lim 2012, Shehzad 2008, Chen \& Li 2019), which focused on niche establishments in RAIs in different disciplines, such as discrete mathematics (Moghaddasi \& Graves 2017), Management (Lim 2012), and Computer Science (Shehzad 2008). However, as the focus of the present study was on niche establishment in RAIs in two different corpora, only Move 2 (Establishing a niche) of Swales' (2004) model was fully applied in the present study. To illustrate, Move 2 contains two steps: Step 1A "Indicating a gap", Step 1B "Adding to what is known", and Step 2 "Presenting positive justification". However, based on the findings of previous research (e.g. Sheldon 2011, Joseph et al. 2014, Farnia \& Barati 2017), Step1A (Identifying a gap) was the most frequently used step. Therefore, it is useful to categorize the rhetorical strategies used to identify a gap in both the international and Thai corpora. In a study by Lim (2012: 237-238), four rhetorical sub-steps for gap identification included "Highlighting the complete absence of research bearing a specific characteristic", "Stressing insufficient research in a specific aspect", "Revealing a limitation in previous research", and "Contrasting conflicting previous research findings in Inconclusiveness". These four rhetorical sub-steps (strategies) were adapted for the present study.

As mentioned earlier, the aims of the present study were to identify Move 2 (Establishing a niche) of RAIs. This demonstrates how authors in different published contexts create their niches linguistically. To avoid possible subjectivity in the results from the move/step analysis, another coder who has experience in move-based analysis and is a university lecturer in the field of applied linguistics was invited to be an inter-rater. The results of the independent coding showed a high inter-rater reliability rate (over 95\%). In the case of differences between the coders, they were discussed, and an agreement was reached by strictly referencing our definition of niche establishment. The frequencies of Move 2 and its steps found in the present study were counted and tabulated. Besides a macro-level identification of move/step analysis, micro-level characteristics in terms of linguistic exponents that signaled the step boundaries were crucial for genre analysis (Reppen \& Simpson 2002). Therefore, the key linguistic resources employed in the boundaries of niche establishments were highlighted.

\section{Results}

\subsection{Frequencies of rhetorical steps}

To answer the first aim of the present research, Table 1 shows the frequency of steps found in both datasets. In order to see clearly how the steps are realized, examples of step boundaries with their key linguistic mechanisms are highlighted. 
The article number from which the example is taken is shown in parentheses, e.g. (Th 1 refers to RAI number 1 from the Thai corpus and In 1 means RAI number 1 from the international corpus). This information is attached at the end of each example.

\begin{tabular}{|l|r|r|}
\hline Move/Step & Frequency \\
\hline & $\begin{array}{l}\text { International Corpus } \\
\mathbf{( N = 4 0 )}\end{array}$ & $\begin{array}{l}\text { Thai Corpus } \\
\mathbf{( N = 4 0 )}\end{array}$ \\
\hline Move Occurrence & $37(92.5 \%)$ & $31(77.5 \%)$ \\
\hline S 1A: Indicating a gap & 34 & 21 \\
\hline S 1B: Adding to what is known & 10 & 3 \\
\hline S 2: Presenting positive justification & 4 & 8 \\
\hline
\end{tabular}

Note $1 . \mathrm{N}=$ refers to the total number of analyzed RAs in this study

Table 1: Frequencies of niche establishment in the RAIs of the two corpora

Table 1 shows the frequencies of niche establishment of RAIs in the two sets of data, accounting for 92.5 and 77.5 per cent in the international and Thai corpora, respectively. A very large difference was found between the two corpora in the use of Step 1B (Adding to what is known). The frequency of Step 1B in the international corpus was over three times higher than that of the Thai corpus. However, compared to the international corpus, the frequency of Step 2 (Presenting positive justification) in the Thai corpus was high, accounting for twice that of the international corpus. This finding clearly indicates the characteristics of niche establishments in the introductory sections of Thai authors.

\begin{tabular}{|l|lr|r|}
\hline Move/Step & \multicolumn{2}{|l|}{ Frequency } \\
\cline { 2 - 4 } & $\begin{array}{l}\text { International Corpus } \\
\mathbf{( N = 4 0 )}\end{array}$ & $\begin{array}{l}\text { Thai Corpus } \\
\mathbf{( N = 4 0 )}\end{array}$ \\
\hline S 1A: Indicating a gap via: & 34 & 21 \\
\hline Sub-steps & $\begin{array}{l}\text { Indicating a complete absence } \\
\text { of research }\end{array}$ & 3 & 6 \\
\cline { 2 - 5 } & Stressing insufficient research & 17 & 14 \\
\cline { 2 - 5 } & $\begin{array}{l}\text { Revealing methodological } \\
\text { limitations }\end{array}$ & 9 & 0 \\
\cline { 2 - 5 } & Indicating inconclusive findings & 9 & 3 \\
\hline
\end{tabular}

Table 2: Frequency of strategies used for indicating a gap between the two corpora

There were some differences in indicating a gap between the two corpora by the authors. In Table 2, four of the sub-steps categorized by Lim (2012) were found in the present study with different degrees of frequency. Indicating 
a gap via "Stressing insufficient research" was highest in ranking of both sets of data, with 17 in the international corpus and 14 in the Thai corpus. There were also differences in the sub-steps of "Revealing methodological limitations" and "Indicating inconclusive findings". These two strategies were mostly used in the international corpus, especially "Revealing methodological limitations" which did not occur in the Thai corpus. Also, the niche establishment via "Indicating inconclusive findings" was three times higher in the international corpus ( 9 versus 3 ). It can be seen that Step 1A (Indicating a gap) via "Stressing insufficient research", was the preferred choice for both corpora, but the other options were clearly different. The functions and their realizations of each step and the strategies for realizing "Indicating a gap" are illustrated below.

\subsection{Realizations of niche establishments}

To respond to the second objective of the present study, namely, how niche establishment was performed in both datasets, this section focuses on linguistic realizations of niche establishments. Lexical items used to signal the boundaries of steps and rhetorical strategies are important, especially in genre-based instructions. Therefore, to have a clear picture on how niches are realized, the realizations with linguistic exponents marked in bold are provided.

\section{Step 1A: Indicating a gap}

Indicating a gap was one of the strategies that the authors used frequently to critically evaluate previous research in order to seek a space for the introduction of their own research. "Indicating a gap" in the present study is manifested by the use of four strategies with different frequencies.

\section{Indicating a complete absence of research}

This rhetorical sub-step consists of negative expressions such as there is no, or none. Examples 1 and 2 below illustrate its realizations. The Thai authors preferred to state the research was missing. Present simple and perfect tenses were frequently found to realize this strategy.

However, there are no known studies that have investigated the use of ... (In 39)

(2) A body of research has observed L2 academic writing..., but none has focused on EFL Thai students. (Th 3)

From Table 2, the frequency of this sub-step in the Thai corpus was found two times higher than that of the international corpus and it ranked second in the Thai corpus. 


\section{Stressing insufficient research}

The most common way to realize this choice was to use negative devices (little, few, hardly) and contradiction connectors (e.g. however, yet, nevertheless, but, although), as shown in Examples 3 and 4. The authors tried to mention the unexplored areas which should be filled by the study being reported. The present tense was used to describe this strategy.

(3) As of yet, relatively little research exists on the grammatical features on organizational structure within stand-alone literature reviews. (In 14)

(4) Nevertheless, there is hardly any research that focuses on the translation of... (Th 12)

It was found that this strategy was similar in occurrence in the two corpora. Among the four choices, this sub-step was ranked number one of each corpus. It occurred in 17 international RAIs and 14 in Thai RAIs.

\section{Revealing methodological limitations}

The rhetorical sub-step called "Revealing a limitation in previous research" as described by Lim (2012) was used to mainly focus on the methodological limitations of previous studies. For example, "the writers' attempt to highlight methodological short-comings in previous studies" (Lim 2012: 237). Therefore, in the present study, the term was slightly modified to "Revealing methodological limitations", which is more appropriate. This means that certain steps or procedures were not taken or considered in the previous research. The past tense was used to realize this strategy. Surprisingly, this strategy was found only in the international corpus.

(5) Besides nature and nurture factors, there is an often-neglected third factor accounting for twin (dis)similarities, i.e. epigenetics, which explains the alteration in the... (In 4)

(6) However, such approaches were criticized for being too reliant on teachers' intuitions about... (In 23)

As shown in Examples 5 and 6, linguistic items, such as criticize and limitation denoted the strategies. In the international corpus, this sub-step was number two in the rank accounting around 41 per cent (14 out of 34), while there was none in the Thai corpus. 


\section{Indicating inconclusive findings}

The fourth sub-step categorized by Lim (2012: 238) was "Contrasting conflicting previous research findings or Inconclusiveness". However, in the present study, only the niche indicating inconclusiveness was found in the corpora. Because of this, the term was adapted to "Indicating inconclusive findings" instead. Writers may initially emphasize some uncertainty about the results of previous research findings and suggest the need to clarify the situation. It was found that raising questions was a possible way to indicate the inconclusiveness. Some authors intended to critically evaluate a previous study by stating that the results were incomplete. This strategy sometimes co-existed with "Revealing methodological limitations". However, there were no specific linguistic indicators to signal the text boundaries. It was found that this sub-step was always expressed via the present simple and present perfect tenses as showed in Examples 7 and 8.

Although differences in duration between nouns and verbs have been widely observed, the question of what is driving these differences has not been conclusively answered. (In 1)

(8) Nevertheless, the exact role of frequency has yet to be clearly understood, particularly, ... (Th 16)

The frequencies of the occurrence in the two corpora were different. There were nine international RAIs contained this sub-step, while only three Thai RAIs addressed this strategy.

\section{Step 1B: Adding to what is known}

The function of this step was to refer to the previous literature without criticizing, questioning, or counter-claiming and the author tried to claim that the current research followed an established research trend or tradition (Lim 2012, Kanoksilapatham 2012, Moghaddasi \& Graves 2017). Since the use of this step was relatively low, not any frequently used or identical key lexical items were used. Its realizations can be seen in Examples 9 and 10.

(9) The present study builds on the above group of studies, rethinking the contents of Jenkins's LFC and proposing a revised version of this list based on empirical data. (In 30)

(10) Previous findings (Rasmusen and Zampini 2012, Ghorbani 2011) have found that to improve intelligibility including listening proficiency, it could be done through studying phonetics. Upon the completion of this research, the researcher intends to answer to the following research questions: ... (Th 40) 
In Example 10 Step 1B coexisted with Move 3 Step 2 (Presenting research questions or hypotheses). This means that the author acknowledged the importance of the topic being stated in the literature and tended to follow that trend in the study being reported.

\section{Step 2: Presenting positive justification}

The function of this step was to demonstrate the need for research or to make a positive evaluation of the study reported. Normally, it always followed the indication of a research gap. As Swales (2004) noted, this step is an optional step. Its occurrence was low in the two datasets, accounting for four RAIs in the international and for eight in the Thai corpora. Examples of Step 2 are given below.

(11) Given the focus of this article on connections between LTI and LTA in the context of and resulting from a specific TESOL program, we hope that the analysis presented below allows for some illumination of these matters. (In 29)

(12) Therefore, it is worth exploring the impact of the explicit teaching of CSs on Thai engineering undergraduates in order to contribute to the research in the field. (Th 19)

\section{Discussion}

Establishing a niche has been focused on in the present study and how the steps of Move 2 (Establishing a niche) proposed by Swales (2004) were realized. The four choices for manifesting the steps were based on Lim's (2012) study. It was found that there were both noticeable similarities and differences in the frequencies of niche establishment in the RAIs of the two corpora, which are discussed below.

It was found that not all RAIs included a niche. This differed from the findings of some previous studies (e.g. Del Saz-Rubio 2011, Lim 2012). These studies found one hundred per cent use of niche establishment in their studies. The present study found that it was used in 92.5 and 77.5 per cent in the international and Thai corpora, respectively. Based on Kanoksilapatham's (2005) criteria of the cut-off point of a move occurrence, ranges of 60-99 per cent indicated a conventional move. Thus, most of the authors in this study, especially in the international corpus, realize the importance of establishing a niche. This high frequency may result from the fact that these RAIs were taken from leading journals, which require rigorous criteria for publication. In other words, in order to qualify for publication in such a highly competitive and global market on 
both content and style, RAs need to situate their niches persuasively. Therefore, writers also need to create their niche establishments clearly and effectively. Most of the Thai authors in this study established their niches. They are clearly aware of the importance of this aspect of writing RAIs. On the other hand, such an awareness may also be a reflection from globalization, which shapes Thai authors to recognize and experience international styles and the genre of RAs. Thus, in order to keep up with the developments in their field, they need to read RAs in English and embrace international practice interculturally and interlingually (Hyland 2005, Sheldon 2011). In doing so, Thai authors can become more familiar with the niche conventions of RAI. However, based on these findings, it is suggested that non-native writers, especially Thai authors need to adopt the established procedures for writing their RAIs, if they wish to have access to international journals.

Compared to Sheldon's (2011) study, RAIs in English written by Spanish speakers showed 77.77 per cent stating a niche in RAIs, which is similar to that found in the Thai corpus in the present study. Sheldon explained that Spanish rhetorical patterns were transferred to English discourse and influenced the writing of RAIs. These non-native authors "are not fully acculturated in the English academic discourse needed for international publication" (ibid.: 245). This may well be the reason for the absence of the establishing a niche in the English RAIs written by non-native English speakers in her study. Similarly, the same situation may also affect Thai authors to some extent because nine RAIs did not contain niches. In addition, the research topic may be another reason for this omission. Research topic remains a large area for future investigation since authors do not have to convince their readers or search for more spaces to situate their research in the field. This can lead to the situation where they prefer to provide more theoretical information rather than evaluating previous research in the field (Ozturk 2007). As found in the present study, the topics of the analyzed RAIs in the Thai corpus are specifically relevant to the Thai context involving local or regional issues, which need more research studies to explore. Also, it should be pointed out, publication in local Thai journals is relatively small in scale compared to that of international journals. The criteria in evaluating manuscripts for local publication tend to be more relaxed and less demanding than those of the popular and recognized international journals (Kanoksilapatham 2007). This can explain why establishing a niche is ignored in nine RAIs in Thai RAIs.

Indicating a gap was the most frequently used step in both corpora, which is in line with those found in previous studies. The frequency of this step ranked number one in research studies in various disciplines such as Forestry (Joseph et al. 2014), Applied Linguistics (Sheldon 2011, Farnia \& Barati 2017), Wildlife 
Behavior (Samraj 2005), Biochemistry (Kanoksilapatham 2005), Discrete Mathematics (Moggaddasi \& Graves 2017) and Computer Science (Shehzad 2008). On looking closely at the strategies used to indicate the gaps, it was found that "Stressing insufficient research" was the most frequently used in both datasets. When the topic being studied is under-explored or insufficient in the field, this is a suitable way to establish a niche that merits attention to the research being reported ( $\operatorname{Lim} 2012$ ). Some adjectives or nouns in the sense of dearth or neglect of research studies are used extensively (e.g. little, less, few, insufficient, under-explored, rarely, limited, etc.) to indicate a gap in both sets of data. Such a "quasi-negative subject" (Swales \& Feak 2004: 258) could help to point out the shortcomings of the research studies in the past and prepare the reader for the need of the current work to be investigated or studied. Examples 13-18 illustrate the employment of these linguistic resources.

(13) To our knowledge, there are relatively few studies that examine the acquisition of two L2 sounds that are both not similar to the sounds of the L1. (In 2)

(14) While the ESP literature has extensively examined strategies for improving English language learning and teaching (e.g. Harding 2007, Paltridge \& Starfield 2013) through specific courses and materials based on careful needs analysis (e.g. Basturkmen 2010), less attention has been paid to the role and impact of subject matter learning through ESP courses. (In 17)

(15) While these studies have revealed the surface forms and rhetorical functions of citations in high-rated disciplinary writers'texts, little is known about the stance student writers take in relation to cited sources. (In 40)

(16) However, previous research investigating the use of second language collocations related to the field of International Business Management (hereafter IBM) is quite limited (Bargiela-Chiappini \& Zhang 2013, Hong, Hua \& Mengyu 2017). (Th 5)

(17) However, oral reading has rarely been tested formally in classrooms in Thailand ... (Th 9)

(18) Research on the topic of hotel undergraduate students' internship was relatively under-explored despite the fact that ... (Th 11)

"Revealing methodological limitations" was another strategy which was used to demonstrate a gap in previous research. As defined, this strategy is used to establish a gap by stating problem(s) in the previous research, such as definition, classification, and methodology (Chen \& Li 2019). However, in the international corpus, this strategy was used when the authors found an incomplete methodology or approach in previous studies. The statements used to realize this 
strategy were always long and descriptive. The authors tried to explain the flaws in previous research methodologies. Surprisingly, this choice was not employed in RAIs written by Thai authors. This may reflect on the specific characteristics of Thai society (Kanoksilapatham 2007). In her study, Kanoksilapatham found no instance of negative comments or evaluation on previous studies by Thai authors. She believed that this was the result of specific Thai characteristics in which direct comments on other people are considered as inappropriate and disrespectful to others. This may also be in line with Khany and Tazik's (2010) notion that evaluating previous research findings with respect to different contexts and situations may not always be valid and acceptable. Perhaps this explains why there is extensive use of "Stressing insufficient research" and less use of direct criticism of other works. This may also support the preferred use of Step 2/2 (Presenting positive justification) in the Thai corpus, which was twice as high as that of the international corpus. A 25 per cent usage of this step reflects the style of writing. It is possible to infer that to some extent Thai cultural characteristics influence Thai authors' written tasks, by not commenting on other works but preferring to state the gaps in previous research and explain the significance of their own research. They prefer to convince the reader that their research findings will be beneficial or fill gaps found in previous studies.

\section{Conclusion}

The results of the analysis of niche establishments made by authors in different published contexts in the present study, which compare niche establishments in RAIs taken from peer reviewed journals in Thailand with those in highly prestigious international journals, yield some valuable insights on how niche establishments are framed in different contexts. These findings will be useful for non-native English speakers, especially Thai authors, to prepare themselves for writing their RAIs. The niche establishments in the two corpora will provide a practical guide for inexperienced writers. The high frequency of occurrence of Move 2 (Establishing a niche) implies that the authors from both sets of data regard niche establishment as an important element of RAIs. The results of this research will be useful for the teaching of both graduates and undergraduates. For example, teachers may integrate the rhetorical structures and linguistic resources suggested in the present study in their writing classes. This will help students to learn how to establish research niches appropriately and effectively when writing their research papers. As this era is highly competitive in the area of research publication or knowledge sharing, students should be prepared with genre-based guidelines to enable them to write up their research for international publication with confidence. 


\section{References}

Ahmed, S. (2015) 'Rhetorical organization of tourism research article abstracts.' Procedia Social and Behavioral Sciences 208, 269-281.

Ali, Z., Syed, G. N. and Saleem, A. (2019) 'Genre analysis of conclusion of research articles of Pakistani and foreign research articles on code mixing and code switching: A comparative study.' International Journal of English Research 5(1), 57-60.

Amirian, Z., Kassaian, Z. and Tavakoli, M. (2008) 'Genre analysis: An investigation of the discussion sections of applied linguistics research articles.' The Asian ESP Journal 4(1), 39-63.

Amnuai, W. and Wannaruk, A. (2013) 'A move-based analysis of the conclusion sections of research articles published in international and Thai journals.' $3 L$ : The Southeast Asian Journal of English Language Studies 19(2), 53-63.

Anthony, L. (1999) 'Writing research article introductions in software engineering: How accurate is a standard model?' IEEE Transactions on Professional Communication 42(1), 38-46.

Armağan, A. (2013) 'How to write an introduction section of a scientific article?' Turkish Journal of Urology 39(1), 8-9.

Brett, P. (1994) 'A genre analysis of the results section of sociology articles.' English for Specific Purposes 22, 365-385.

Bruce, I. (2014) 'Expressing criticality in the literature review in research article introductions in applied linguistics and psychology.' English for Specific Purposes 36, 85-96.

Chang, P. and Schleppegrell, M. (2011) 'Taking an effective authorial stance in academic writing: Making the linguistic resources explicit for L2 writers in the social sciences.' Journal of English for Academic Purposes 10, 140-151.

Chen, X. and Li, M. (2019) 'Chinese learner writers' niche establishment in the literature review chapter of theses: A diachronic perspective.' Journal of English for Academic Purposes 39, 48-58.

Cotos, E., Huffman, S. and Link, S. (2017) 'A move/step model for methods sections: Demonstrating rigour and credibility.' English for Specific Purposes 46, 90-106.

Del Saz-Rubio, M. M. (2011) 'A pragmatic approach to the macro-structure and metadiscoursal features of research article introductions in the field of agricultural sciences.' English for Specific Purposes 30(4), 258-271.

Duszak, A. (1997) 'Cross-cultural academic communication: A discourse-community view.' In: Duszak, A. (ed.) Intellectual Styles and Cross-cultural Communication. Berlin: Mouton de Gruyter. 11-41.

Farnia, M. and Barati, S. (2017) 'Writing introduction sections of research articles in applied linguistics: Cross-linguistic study of native and non-native writers.' Indonesian Journal of Applied Linguistics 7(2), 486-494.

Flowerdew, J. (1999) 'Writing for scholarly publication in English: The case of Hong Kong.' Journal of Second Language Writing 8(2), 123-45.

Hyland, K. (2000) Disciplinary Discourses: Social Interactions in Academic Writing. Harlow: Pearson Education.

Hyland, K. (2005) Metadiscourse: Exploring Interaction in Writing. London: Continuum.

Joseph, R., Lim, J. M. H. and Nor, N. A. M. (2014) 'Communicative moves in forestry research Introductions: Implications for the design of learning materials.' ProcediaSocial and Behavioral Sciences 134, 53-69. 


\section{Niche Establishments in Research Article Introductions \\ IN INTERNATIONAL AND THAI JOURNALS}

Kanoksilapatham, B. (2005) 'Rhetorical structure of biochemistry research articles.' English for Specific Purposes 24, 269-292.

Kanoksilapatham, B. (2007) 'Writing scientific research articles in Thai and English: Similarities and difficulties.' Silpakorn University International Journal 7, 172-203.

Kanoksilapatham, B. (2012) 'Structure of research article introductions in three engineering subdisciplines.' IEEE Transactions on Professional Communication 55(4), 294-309.

Khany, R. and Tazik, K. (2010 'A comparative study of introduction and discussion sections of sub-disciplines of applied linguistics research articles.' Journal of Research in Applied Linguistics 1(2), 97-122.

Lim, J. M. H. (2006) 'Method sections of management research articles: A pedagogically motivated qualitative study.' English for Specific Purposes 25(3), 282-309.

Lim, J. M. H. (2012) 'How do writers establish research niches? A genre-based investigation into management researchers' rhetorical steps and linguistic mechanisms.' Journal of English for Academic Purposes 11, 229-245.

Liu, Y. and Buckingham, L. (2018) 'The schematic structure of discussion sections in applied linguistics and the distribution of metadiscourse markers.' Journal of English for Academic Purposes 34, 97-109.

Loi, C. K. (2010) 'Research article introductions in Chinese and English: A comparative genre-based study.' Journal of English for Academic Purposes 9(4), 267-279.

Loi, C. K., and Evans, M. S. (2010) 'Cultural differences in the organization of research article introductions from the field of educational psychology: English and Chinese.' Journal of Pragmatics 42(10), 2814-2825.

Moghaddasi, S. and Graves, H. A. B. (2017) “"Since Hadwiger's conjection... is still open": Establishing a niche for research in discrete mathematics research article introductions.' English for Specific Purposes 45, 69-85.

Ozturk, I. (2007) 'The textual organization of research article introductions in applied linguistics: Variability within a single discipline.' English for Specific Purposes 26(1), 25-38.

Peacock, M. (2011) 'The structure of the methods section in research articles across eight disciplines.' Asian ESP Journal 7(2), 99-124.

Pho, P. D. (2008) 'Research article abstracts in applied linguistics and educational technology: A study of linguistic realizations of rhetorical structure and authorial stance.' Discourse Studies 10(2), 231-250.

Reppen, R. and Simpson, R. (2002) 'Corpus linguistics.' In: Schmitt, N. (ed.) An Introduction to Applied Linguistics. New York: Oxford University Press. 92-111.

Samraj, B. (2002) 'Introductions in research articles: Variations across disciplines.' English for Specific Purposes 21(1), 1-17.

Samraj, B. (2005) 'An exploration of a genre set: Research article abstracts and introductions in two disciplines.' English for Specific Purposes 24(2), 141-156.

Scimago journal and Country Rank. (2018) Accessed on 15 March $2020<$ https://www. scimagojr.com/journalrank.php>.

Shehzad, W. (2008) 'Move two: Establishing a niche.' Iberica 15, 25-50.

Sheldon, E. (2011) 'Rhetorical differences in RA introductions written by English L1 and L2 and Castilian Spanish L1 writers.' Journal of English for Academic Purposes 10, 238-251.

Swales, J. M. (1990) Genre Analysis: English in Academic and Research Settings. Cambridge: Cambridge University Press. 
Swales, J. M. (2004) Research Genres: Explorations and Applications. Cambridge: Cambridge University Press.

Swales, J. M. and Feak, C. B. (2004) Academic Writing for Graduate Students: Essential Tasks and Skills. $2^{\text {nd }}$ ed. Ann Arbor, MI: The University of Michigan Press.

Thompson, D. K. (1993) 'Arguing for experimental 'fact' in science: A study of research article results sections in biochemistry.' Written Communication 10(1), 106-128.

Valero-Garces, C. (1996) 'Contrastive ESP rhetoric: Metatext in Spanish-English economics texts.' English for Specific Purposes 16(4), 279-294.

Williams, I. A. (1999) 'Results sections of medical research articles: Analysis of rhetorical categories for pedagogical purposes.' English for Specific Purposes 18(4), 347-366

Yang, R. and Allison, D. (2003) 'Research articles in applied linguistics: Moving from results to conclusions.' English for Specific Purposes 22(4), 365-385.

Yang, R. and Allison, D. (2004) 'Research articles in applied linguistics: Structure from a functional perspective.' English for Specific Purposes 23(3), 264-279.

Zamani, G. and Ebadi, S. (2016) 'Move analysis of the conclusion sections of research papers in Persian and English.' Cypriot Journal of Educational Sciences 11(1), 9-22.

Zhang, B. and Wannaruk, A. (2016) 'Rhetorical structure of education research article methods sections.' PASAA 51, 155-184.

Wirada Amnuai is Assistant Professor at the Department of Humanities at Rajamangala University of Technology Isan, Nakhon Ratchasima, Thailand. Her research interests include discourse and genre analysis, disciplinary and classroom discourses, and second language writing.

Address: Wirada Amnuai, Department of Humanities, Faculty of Sciences and Liberal Arts, Rajamangala University of Technology Isan, Nakhon Ratchasima, Thailand 30000. [e-mail: wamnuai@gmail.com] 